\title{
Hidroresfriamento e embalagens na conservação pós-colheita de cebolinha (Allium schoenoprasum)
}

\section{Hydrocooling and packaging in the post-harvest conservation of chives (Allium schoenoprasum)}

Antônia Mirian Nogueira de Moura Guerra

Universidade Federal do Oeste da Bahia

E-mail: mirianagronoma@hotmail.com

OrclD: https://orcid.org/0000-0001-9475-306X

Deyse Silva dos Santos

Universidade Federal do Oeste da Bahia

E-mail: deys@hotmail.com

OrcID: https://orcid.org/0000-0002-5509-7327

Priscila Santos Silva

Universidade Federal do Oeste da Bahia

E-mail: prisccila@hotmail.com

OrcID: https://orcid.org/0000-0001-9905-3310

Lucas Barbosa dos Santos

Universidade Federal do Oeste da Bahia

E-mail: lluccassantos@hotmail.com

OrcID: https://orcid.org/0000-0001-9736-9303

Maria Gabriela Magalhães Silva

Universidade Federal do Oeste da Bahia

E-mail: gaby@hotmail.com

OrclD: https://orcid.org/0000-0001-5878-634X

Resumo: A cebolinha é uma hortaliça folhosa altamente perecível, a intensa perda de água e a rápida deterioração lhe confere uma conservação de poucos dias, sendo necessário o uso de técnicas capazes de prolongar a sua vida útil pós-colheita. Desse modo, objetivou-se com a realização do presente trabalho avaliar a influência das condições de armazenamento sobre a vida útil pós-colheita da cebolinha. Adotou-se um experimento com delineamento inteiramente casualizado em esquema fatorial 6x9 em parcelas subdivididas com três repetições, nas parcelas foram alocadas as condições de armazenamento e na subparcela os períodos de avaliação, sendo cada unidade experimental constituída por um maço com 24 folhas. As condições de armazenamento foram: sem hidroresfriamento e sem embalagem, sem hidroresfriamento e embalagem plástica, sem hidroresfriamento e PVC, hidroresfriamento sem embalagem plástica, hidroresfriamento e embalagem plástica e hidroresfriamento e PVC e armazenados a $10 \pm 2{ }^{\circ} \mathrm{C}$. Foram armazenadas por 0, 2, 4, 6, 8, 10, 12, 14 e 16 dias consecutivos. Foram avaliadas vida de prateleira, perda de massa fresca, teor relativo de água, clorofila total e carotenoides. Observou-se na embalagem plástica e filme PVC, independente do pré-resfriamento, menor perda de massa e aumento de 16 dias na vida de prateleira. $\mathrm{O}$ teor relativo de água foi influenciado pelas condições e o tempo de armazenamento. $\mathrm{O}$ teor de clorofila das folhas reduziu ao longo dos dias de armazenamento à $10{ }^{\circ} \mathrm{C}$, independentemente do tratamento. $\mathrm{O}$ hidroresfriamento associado às embalagens e a temperatura de armazenamento foram eficientes em reduzir, temporariamente, a degradação da clorofila e o teor de carotenoides. Dessa forma, recomenda-se a adoção de embalagem plástica ou filme PVC associado ao hidroresfriamento por 30 minutos, como alternativa para prolongar a vida pós-colheita das cebolinhas.

Palavras-chave: Atmosfera modificada; Hortaliça; Pré-resfriamento. 
Abstract: Chives are a highly perishable leafy vegetable, the intense loss of water and the rapid deterioration gives it a conservation of few days, being necessary the use of techniques capable of prolonging its postharvest useful life. Thus, the objective of this study was to evaluate the influence of storage conditions on the post-harvest useful life of chives. An experiment was adopted in a completely randomized design in a 6x9 factorial scheme in plots subdivided with three replications, in the plots the storage conditions were allocated and in the subplot the evaluation periods, with each experimental unit consisting of a pack of 24 leaves. The storage conditions were without hydrocooling and without packaging, without hydrocooling and plastic packaging, without hydrocooling and PVC, hydrocooling without plastic packaging, hydrocooling and plastic and hydrocooling packaging and PVC and stored at $10 \pm 2{ }^{\circ} \mathrm{C}$. They were stored for $0,2,4,6,8,10,12,14$ and 16 consecutive days. Shelf life, loss of fresh weight, relative water content, total chlorophyll and carotenoids were evaluated. It was observed in the plastic packaging and PVC film, independent of precooling, less loss of mass and an increase of 16 days in shelf life. The relative water content was influenced by the conditions and the storage time. The chlorophyll content of the leaves decreased during the storage days at $10{ }^{\circ} \mathrm{C}$, regardless of the treatment. Hydrocooling associated with packaging and storage temperature were effective in temporarily reducing chlorophyll degradation and carotenoid content. Thus, it is recommended to adopt plastic packaging or PVC film associated with hydrocooling for 30 minutes, as an alternative to prolong the post-harvest life of chives.

Keywords: Modified atmosphere; Vegetable; Pre-cooling.

Data de recebimento: $25 / 02 / 2019$

Data de aprovação: 16/06/2020

DOI: https://doi.org/10.30612/agrarian.v13i50.9478

\section{Introdução}

A cebolinha (Allium schoenoprasum) é uma planta pertencente à família Aliaceae que possui folhas cilíndricas e fistulosas, com 0,30 a 0,50 m de altura e coloração verde-escura, produz pequeno bulbo cônico, envolvido por película rósea, com perfilhamento e formação de touceira (HEREDIA \& VIEIRA, 2004). Essa hortaliça é considerada um condimento muito apreciado pela população brasileira, sendo comumente comercializada com outras folhosas como o coentro (Coriandum sativum L.) (SANTANA, 2015).

De acordo com Chitarra e Chitarra (2005), as perdas pós-colheita são aquelas que ocorrem após a colheita em decorrência da falta de comercialização ou do consumo do produto em tempo hábil. Essas perdas podem ser de natureza quantitativa (perda de massa), qualitativa (perdas no sabor, aroma e deterioração na textura e na aparência) e nutricional.

No Brasil, perdas pós-colheita de frutas e hortaliças são estimadas entre $40-50 \%$ da produção (GUSTAVSSON et al., 2011; FERREIRA, 2017). Iniciando-se logo após a colheita até a chegada à mesa do consumidor, as perdas ocorrem devido a injúrias mecânicas, patológicas e fisiológicas (PARISI et al., 2012), que são favorecidas pelo manuseio, transporte e condições de armazenamento inadequadas.

As hortaliças folhosas são altamente perecíveis, devido a intensa perda de água e a rápida deterioração que atribui a esses produtos uma conservação de poucos dias após serem colhidos, sendo necessário o uso de técnicas capazes de prologar a sua vida útil pós-colheita (FINGER et al., 1999; FRANÇA et al., 2015).

A perda de massa das hortaliças ocorre principalmente devido à altas taxas transpiratórias e ao processo de respiração desses produtos durante 0 armazenamento. $O$ enrugamento dos tecidos, amaciamento da polpa e perda de massa fresca das hortaliças são ocasionados pela excessiva perda de água na pós-colheita. Desse modo, a perda de água é um importante fator econômico na comercialização feita com base na massa de matéria fresca (VILA, 2004).

O uso de atmosfera modificada durante o armazenamento, promove decréscimo na velocidade da respiração, retardo na maturação e redução na deterioração de frutas e hortaliças, uma vez que essa modificação na atmosfera é caracterizada pela formação de uma barreira artificial à difusão de gases em torno da hortaliça ou fruta, resultando numa redução do nível de $\mathrm{O}_{2}$ aumento do nível de $\mathrm{CO}_{2}$ e aumento do teor de vapor d'água (MACHADO, et al., 2007; CERQUEIRA, 2007; CHRISTIE et al., 1995; KADER et al., 1989).

A modificação da atmosfera pode ser obtida utilizando-se embalagens de materiais plásticos, como polietileno, policloreto de vinila e similares ou através da aplicação de produtos, como ceras, ésteres de 
sacarose e outros aditivos (KLUGE et al., 2002; MACHADO, et al., 2007). Dessa forma, o uso de embalagens adequadas além de proteger, pode auxiliar na conservação pós-colheita de hortaliças.

Em estudos sobre a conservação pós-colheita de pimentas-de-cheiro (Capsicum chinense) armazenadas sob atmosfera modificada e refrigeração, Cerqueira (2012) constatou que a embalagem saco de polietileno proporcionou menor perda de massa das pimentas-de-cheiro armazenadas durante 12 dias. Arruda et al. (2004) observaram que raízes de beterraba recobertas com filme PVC e armazenadas a $20^{\circ} \mathrm{C}$ apresentaram menor perda de massa e pressão de turgescência e prologaram o seu período de conservação por mais de 9 dias. Estudos como estes apontam o uso de atmosfera modificada na melhoria da vida de armazenamento de frutas e hortaliças.

A temperatura é um dos principais fatores que afetam a vida pós-colheita e qualidade de frutas e hortaliças, visto que a perda da qualidade observada nos vegetais após serem colhidos é em decorrência de processos fisiológicos e bioquímicos que são influenciados primariamente pela temperatura do produto (ÁLVARES, 2006). É recomendável o uso de método que retarde os processos de deterioração, o que inclui o pré-resfriamento antes do armazenamento refrigerado. Este procedimento mantém a qualidade de hortaliças, por retirar rapidamente o calor de campo dos produtos antes de serem comercializados, armazenados ou processados, o que aconteceria de forma lenta e gradativa em câmara fria (BECKER \& FRICKE, 2002). Isto controla mais rapidamente as taxas de respiração, transpiração, a senescência e a produção de etileno (KALBASI-ASHTARI, 2004).

O hidroresfriamento é uma entre as técnicas de pré-resfriamento que consiste na utilização de água gelada ou fria para reduzir a temperatura do produto antes de ser embalado e refrigerado. Trata-se de um método simples, prático e eficiente que traz como um dos seus benefícios a prevenção da perda de umidade durante o processo de resfriamento (WILLS et al., 1998; FRANÇA et al., 2015).

$\mathrm{O}$ uso do hidroresfriamento e atmosfera modificada têm demonstrado efeitos positivos na conservação pós-colheita de frutas e hortaliças. Souza et al. (2017) observaram que o hidroresfriamento à $5^{\circ} \mathrm{C}$ por 15 minutos foi efetivo na manutenção da qualidade físico-química de folhas de coentro até $\circ 8^{\circ}$ dia de armazenamento refrigerado. Álvares (2006) constatou que embalagens PET (Politereftalato de etileno) sem perfuração proporcionam maior qualidade e maior longevidade em folhas de salsinha previamente hidratadas. Contudo, para cebolinha, existem poucas informações acerca de métodos de conservação pós-colheita, fazendo-se necessário a realização de estudos que busquem apontar condições de armazenamento que permitam estocar essa hortaliça por um período sem comprometer a sua qualidade. Dessa forma, o objetivo do trabalho foi avaliar a influência das condições de armazenamento, envolvendo hidroresfriamento associado a diferentes embalagens, sobre a vida útil pós-colheita de cebolinhas.

\section{Material e Métodos}

O experimento foi conduzido no laboratório multidisciplinar do Campus de Barra - BA, da Universidade Federal do Oeste da Bahia - UFOB. As folhas de cebolinha foram produzidas na área de produção de hortaliças do Campus de Barra - BA durante o período de 60 dias, seguindo recomendações de Filgueira (2008). Posteriormente, foram colhidas e conduzidas ao laboratório para a realização dos experimentos.

No laboratório, as folhas passaram pelo processo de seleção e padronização para eliminação daquelas com danos mecânicos, fisiológicos e ataque de insetos. As cebolinhas foram arranjadas em maços com 24 folhas e em seguida foi aferida a temperatura dos maços com termômetro infravermelho. Posteriormente, os maços que passaram por hidroresfriamento foram imersos em caixas de isopor contendo água com gelo na proporção de $1: 3(\mathrm{v} / \mathrm{v})$ a $4{ }^{\circ} \mathrm{C}$. A cada 5 minutos, foram retirados dois maços e medida a temperatura. $\mathrm{O}$ tempo do hidroresfriamento foi determinado com a estabilização da temperatura, conforme descrito por Travassos et al. (2017). Conhecido o tempo necessário de imersão em água com gelo a $4{ }^{\circ} \mathrm{C}$, todos os maços destinados ao hidroresfriamento foram submetidos a esse tratamento, enquanto os demais foram apenas submersos em água destilada a temperatura ambiente. Após a aplicação do resfriamento hidrotérmicos, as folhas passaram por secagem a temperatura ambiente para retirada do excedente de água retido em sua superfície, sendo dispostas em bandejas plásticas forradas com papel toalha, logo depois foram embalados. Em seguida, foram armazenados em refrigerador a temperatura de $10 \pm 2{ }^{\circ} \mathrm{C}$.

Adotou-se no experimento o delineamento inteiramente casualizado em esquema fatorial $6 \times 9$ em parcelas subdivididas com três repetições, nas parcelas foram alocadas as condições de armazenamento e na subparcela os períodos de avaliação, sendo cada unidade experimental constituída por um maço com 24 folhas. Os fatores foram constituídos pelas condições de armazenamento (que envolveram hidroresfriamento 
e embalagens) e os períodos de armazenamento. As condições de armazenamento foram: (1) sem hidroresfriamento e sem embalagem, (2) sem hidroresfriamento + embalagem plástica, (3) sem hidroresfriamento + PVC, (4) hidroresfriamento sem embalagem, (5) hidroresfriamento + embalagem plástica e (6) hidroresfriamento + PVC e armazenados a $10 \pm 2{ }^{\circ} \mathrm{C}$. Os períodos de armazenamento foram de $0,2,4$, $6,8,10,12,14$ e 16 dias consecutivos.

O experimento foi conduzido em duplicata para atender análises destrutivas e não destrutivas ao longo do período de armazenamento. As avaliações contemplaram: (1) análise visual e vida de prateleira, (2) perda de massa de folhas frescas, (3) teor relativo de água e (4) teor de clorofila, sendo que as duas primeiras foram não destrutivas, e as demais destrutivas.

Para a análise visual e vida de prateleira os maços de cebolinha foram avaliados desde o momento da coleta e da aplicação dos tratamentos (tempo 0) até o fim do período de prateleira, por meio de notas subjetivas. Todos os maços submetidos ao experimento apresentaram nota 0 . $\mathrm{O}$ descarte ocorreu quando os maços receberam nota 3, que equivale a condições impróprias à comercialização e fim da vida de prateleira.

As notas atribuídas constaram de 0 a 3, conforme Travassos et al. (2017) com modificações. Nota 0: ausência total de murcha, amarelecimento, oxidação, ataque de insetos ou outro sinal visual indicativo de perda de qualidade. Nota 1: surgimento leve de murcha na ponta das folhas (entre 1 e $2 \mathrm{~cm}$ de comprimento), acompanhada ou não de amarelecimento e/ou oxidação, ou outro sinal visual indicativo de perda de qualidade. Nota 2: progressão da murcha ao longo das folhas, acompanhada ou não de amarelecimento e/ou oxidação, sendo viável para consumo desde que retirada a parte danificada. Nota 3: folhas completamente murchas, acompanhada ou não de amarelecimento e/ou oxidação, impróprios à comercialização/consumo e determinado o fim da vida de prateleira.

Durante o armazenamento os maços de cebolinha foram pesados a cada dois dias até o término do período da vida de prateleira, estabelecido junto à análise visual. Os dados foram expressos em porcentagem, considerando a diferença entre a massa inicial e a massa obtida a cada intervalo de tempo. Os dados foram transformados em perda de massa fresca acumulada (MORETTI, 2006).

O teor relativo de água das folhas (TRA) foi avaliado na instalação do experimento (tempo 0) e a cada 2 dias. Realizou-se o corte de oito seções de aproximadamente $1 \mathrm{~cm}^{2}$ as quais foram pesadas e obtida a massa fresca (MF). As mesmas seções foram hidratadas em espuma de poliuretano de $2 \mathrm{~cm}$ de espessura até a porcentagem máxima de hidratação ( 9 horas). As espumas foram mantidas umedecidas com água destilada evitando o ressecamento. Após esse período, as seções foram novamente pesadas e obtidas à massa túrgida (MT) e em seguida foram levadas à estufa com circulação forçada de ar à $70^{\circ} \mathrm{C}$ e obtida a massa seca (MS). O teor relativo de água (TRA) das folhas foi estimado conforme descrito por Catsky (1974), com equação citada por Weatherley (1950):

$$
T R A=\left[\frac{(M F-M S)}{(M T-M S)}\right] \times 100
$$

Em que: TRA = teor relativo de água $(\%) ; M F=$ massa fresca $(\mathrm{g}) ; \mathrm{MS}=$ massa seca $(\mathrm{g}) ; \mathrm{MT}=$ massa túrgida (g).

O teor de clorofila foi avaliado na instalação do experimento (tempo 0) e a cada 2 dias. Amostras de $0,3 \mathrm{~g}$ das folhas foram maceradas em nitrogênio líquido $\left(\mathrm{N}_{2}\right)$ contendo $0,01 \mathrm{~g}$ de carbonato de cálcio e, em seguida, homogeneizadas com $5 \mathrm{~mL}$ de acetona $80 \%(\mathrm{v} / \mathrm{v})$ por 1 minuto. A suspensão resultante foi filtrada em papel filtro. O resíduo foi lavado três vezes em acetona a $80 \%$ e o volume final completado em balão volumétrico para $25 \mathrm{~mL}$, com o mesmo solvente. Todo o processo de extração ocorreu sob penumbra. As absorbâncias dos extratos foram lidas em espectrofotômetro nos comprimentos de onda 470, 646,8 e 663,2 $\mathrm{nm}$. As concentrações de clorofila a (Cla), clorofila b $(\mathrm{Clb})$, carotenoides e pigmentos totais, bem como a metodologia de extração de pigmentos seguiram orientações conforme Lichtenthaler (1987).

Os dados obtidos foram submetidos à análise de variância (ANOVA), sendo as diferenças de médias entre os tratamentos comparadas pelo teste de Tukey ao nível de $5 \%$ de probabilidade, e para tal procedimento utilizou-se o programa estatístico Sisvar versão 5.6 (FERREIRA, 2019).

\section{Resultados e Discussão}


Houve efeito das condições de armazenamento sobre a vida útil pós-colheita de cebolinhas (Figura 1). Aos 6 dias de armazenamento foi determinado o fim da vida pós-colheita dos maços de cebolinhas que foram armazenados a granel, tanto daqueles que foram hidroresfriados, quanto aqueles que foram imersos em água destilada, sendo estes eliminados. Já os maços submetidos aos demais tratamentos se mantiveram em condições de consumo até o final do período de armazenamento, indicando que a conservação das folhas de cebolinha ocorreu devido à modificação da atmosfera de vivência desta hortaliça, promovida pelas embalagens (Figura 1). Estes resultados se assemelham aos encontrados por Cerqueira (2012), Arruda et al. (2004) e Álvares (2006), estes constataram que embalagem de saco de polietileno, filme PVC e embalagens PET, prologaram o período de conservação de pimentas-de-cheiro, raízes de beterraba e folhas de salsinha, respectivamente.

Resultados como estes comprovam que o uso da atmosfera modificada promove a preservação da qualidade de frutas e hortaliças, por contribuir para a redução da atividade metabólica e da perda de água, melhorando o seu aspecto comercial, bem como aumentando a vida útil do produto durante a comercialização (VILA, 2004; CERQUEIRA, 2012). Vale ressaltar que a vida útil das hortaliças também é afetada pela a temperatura, uma vez que o ambiente refrigerado além de diminuir o processo de respiração, pode reduzir à ação das enzimas, a perda de água e a ação dos microrganismos que provocam deterioração e assim aumentar a vida útil de destes produtos (CERQUEIRA, 2012). Dessa forma, é possível afirmar que o armazenamento a $10^{\circ} \mathrm{C}$ contribuiu para o aumento da vida útil pós-colheita das cebolinhas.

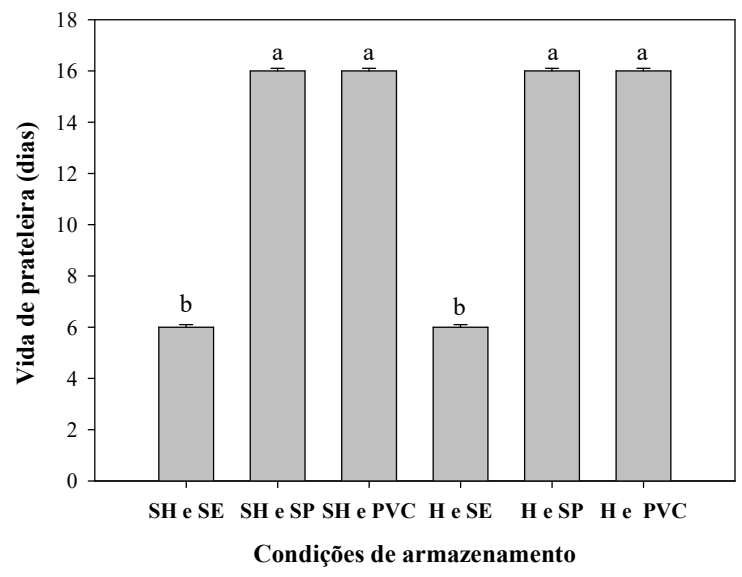

Figura 1. Efeito das condições de armazenamento sobre a vida útil pós-colheita de cebolinhas (Allium schoenoprasum). SH e SE: sem hidroresfriamento e sem embalagem; SH e SP: sem hidroresfriamento e saco plástico; SH e PVC: sem hidroresfriamento e PVC; $H$ e SE: hidroresfriamento sem embalagem; $\mathrm{H}$ e SP: hidroresfriamento e saco plástico; H e PVC: hidroresfriamento e PVC. Médias seguidas pela mesma letra não diferem entre si pelo Teste de Tukey ao nível de 5\% de probabilidade.

Houve aumento da perda de massa ao longo do período de armazenamento a $10{ }^{\circ} \mathrm{C}$, independente da condição de armazenamento (Figura 2). Na maioria das hortaliças folhosas a perda de massa fresca entre $5 \%$ e 10\%, promove rápido declínio da qualidade pós-colheita (TRAVASSOS et al., 2017). As folhas de cebolinhas embaladas tanto com filme PVC, quanto com saco plástico, hidroresfriadas ou não, apresentaram perdas abaixo desta faixa ao longo do armazenamento, chagando ao final do armazenamento em condições de serem comercializadas, visto que foram observadas perdas de massa inferiores à $5 \%$ até o $14^{\circ}$ dia nos tratamentos com embalagens, independente do hidroresfriamento, sendo constatado perdas máximas de $6,16 \%$ no último dia de armazenamento apenas nas cebolinhas sem hidroresfriamento e embaladas com PVC. Nos tratamentos sem hidroresfriamento sem embalagem e com hidroresfriamento sem embalagem, constataram-se perdas de massa de 17,20\% e 29,03\%, respectivamente, aos 6 dias de armazenamento, momento em que foram eliminados. A menor perda de massa foi observada no tratamento sem hidroresfriamento com saco plástico $(4,1 \%)$ no $16^{\circ}$ dia de armazenamento (Figura 2).

Não foram observadas diferenças quanto à perda de massa, entre as folhas dos tratamentos que foram hidroresfriados e aqueles que não foram hidroresfriados antes do armazenamento, com exceção dos tratamentos que foram embalados à granel. Álvares (2006) observou resultado diferente, constatando que o 


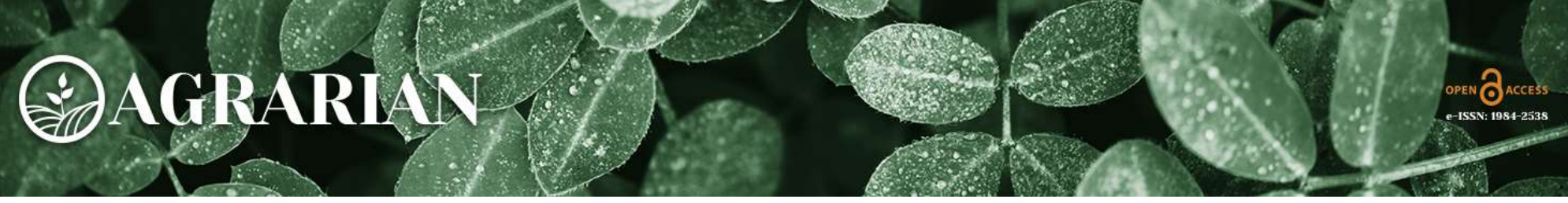

pré-resfriamento por 15 minutos com água gelada após a colheita foi efetivo em reduzir a perda de massa das folhas de salsinha nas primeiras 12 horas de armazenamento a $5^{\circ} \mathrm{C}$ com rápido murchamento das folhas que não foram pré-resfriadas. Já França et al. (2015) observaram maior taxa de perda de massa em cabeças de alface 'Lucy Brown' hidroresfriadas e armazenadas à $5^{\circ} \mathrm{C}$ e à $22^{\circ} \mathrm{C}$, quando comparadas com aquelas que não foram submetidas ao hidroresfriamento.

Perdas de água excessivas provocam o desenvolvimento de estresse hídrico das folhas e, consequentemente, aceleram a senescência destas (LAZAN et al., 1987; ÁLVARES, 2006). Os principais sinais da demasiada perda de água são o murchamento e o enrugamento dos tecidos, além do aceleramento do processo de deterioração, devido ao aumento da taxa de algumas reações de origem predominantemente catabólicas (FINGER \& VIEIRA, 1997; ÁLVARES, 2006).

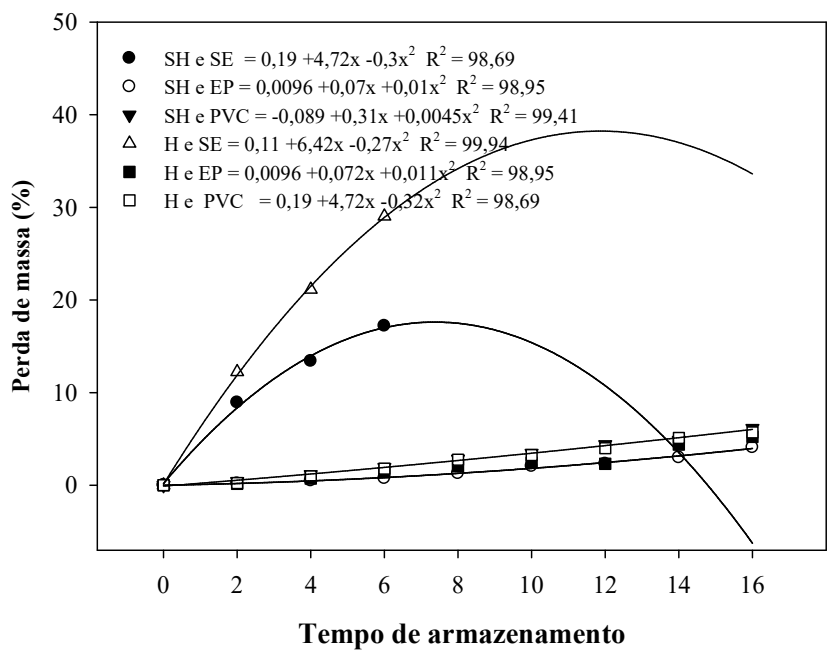

Figura 2. Efeito das condições (hidroresfriamento e embalagens) e do tempo de armazenamento sobre sobre as variações de perda de massa (\%) das folhas (Allium schoenoprasum). SH e SE: sem hidroresfriamento e sem embalagem; SH e SP: sem hidroresfriamento e saco plástico; SH e PVC: sem hidroresfriamento e PVC; $\mathrm{H}$ e SE: hidroresfriamento sem embalagem; $\mathrm{H}$ e SP: hidroresfriamento e saco plástico; H e PVC: hidroresfriamento e PVC. ${ }^{* *}$ : significativo ao nível de $1 \%$ de probabilidade pelo teste $F$.

Os primeiros sinais de murchamento expressaram-se visivelmente a partir do $2^{\circ}$ dia durante o período experimental para os tratamentos sem hidroresfriamento sem embalagem e com hidroresfriamento sem embalagem, e a partir do $6^{\circ}$ dia para os demais tratamentos (Figura 3). Foram atribuídas notas 2 e 1 para as cebolinhas embaladas com plástico e PVC, respectivamente, até o final do armazenamento, evidenciando que mesmo as folhas de cebolinhas apresentando sinais progressivos de perda de qualidade, aos 16 dias ainda estavam aptos para consumo (Figura 3).

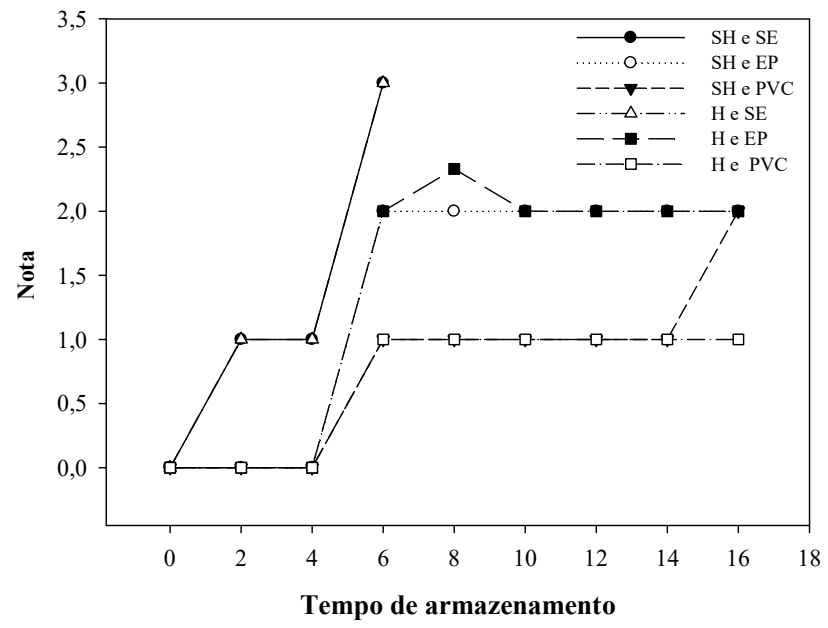

Agrarian, Dourados, v. 13, n. 50, p. 567-576, 2020. 
Figura 3. Efeito das condições (hidroresfriamento e embalagens) e do tempo de armazenamento sobre notas atribuídas na análise visual das folhas (Allium schoenoprasum). SH e SE: sem hidroresfriamento e sem embalagem; SH e EP: sem hidroresfriamento e embalagem plástica; SH e PVC: sem hidroresfriamento e PVC; H e SE: hidroresfriamento sem embalagem; $\mathrm{H}$ e EP: hidroresfriamento e embalagem plástica; H e PVC: hidroresfriamento e PVC.

Houve efeito dos tratamentos no teor relativo de água ao longo do armazenamento (Tabela 2). O teor relativo de água das folhas foi maior no tratamento sem hidroresfriamento e sem embalagem, sendo aproximadamente $10 \%$ maior que a média do TRA dos demais tratamentos. Foi constatada uma variação no TRA dos tratamentos ao longo dos dias, sendo observada uma redução de $38,95 \%$ do tempo 0 para o $2^{\circ}$ dia e reduções em proporções menores nos demais dias de armazenamento (Figura 4).

Tabela 2. Efeito das condições de armazenamento e tempos de armazenamento sobre o teor relativo de água (TRA - \%), teor de clorofilas totais e teor de carotenoides durante armazenamento maços de cebolinha (Allium schoenoprasum).

\begin{tabular}{lccc}
\hline & $\begin{array}{c}\text { TRA } \\
(\%)^{* *}\end{array}$ & $\begin{array}{c}\text { Clorofilas totais } \\
\text { (mg/g Massa Fresca) }^{* *}\end{array}$ & $\begin{array}{c}\text { Carotenoides } \\
\text { (mg/g Massa Fresca) }\end{array}$ \\
\hline Condições de armazenamento & & & \\
\hline Sem hidroresfriamento e sem embalagem & $104,96 \mathrm{a}$ & $2,641 \mathrm{ab}$ & $1,118 \mathrm{a}$ \\
Sem hidroresfriamento e sem embalagem & $93,56 \mathrm{~b}$ & $2,106 \mathrm{~b}$ & $0,896 \mathrm{ab}$ \\
Sem hidroresfriamento e PVC & $98,21 \mathrm{ab}$ & $2,015 \mathrm{~b}$ & $0,906 \mathrm{ab}$ \\
Hidroresfriamento sem embalagem & $95,19 \mathrm{~b}$ & $3,223 \mathrm{a}$ & $0,801 \mathrm{~b}$ \\
Hidroresfriamento e sem embalagem & $93,19 \mathrm{~b}$ & $1,860 \mathrm{~b}$ & $0,690 \mathrm{~b}$ \\
Hidroresfriamento e PVC & $95,11 \mathrm{~b}$ & $2,383 \mathrm{ab}$ & $0,642 \mathrm{~b}$ \\
\hline DMS & 8,81 & 0,944 & 0,267 \\
CV $(\%)$ & 9,73 & 24,57 & 24,75 \\
\hline
\end{tabular}

Médias seguidas pela mesma letra, minúscula na coluna, não diferem entre si pelo Teste de Tukey ao nível de $5 \%$ de probabilidade.

**: significativo ao nível de $1 \%$ de probabilidade pelo teste $F$.

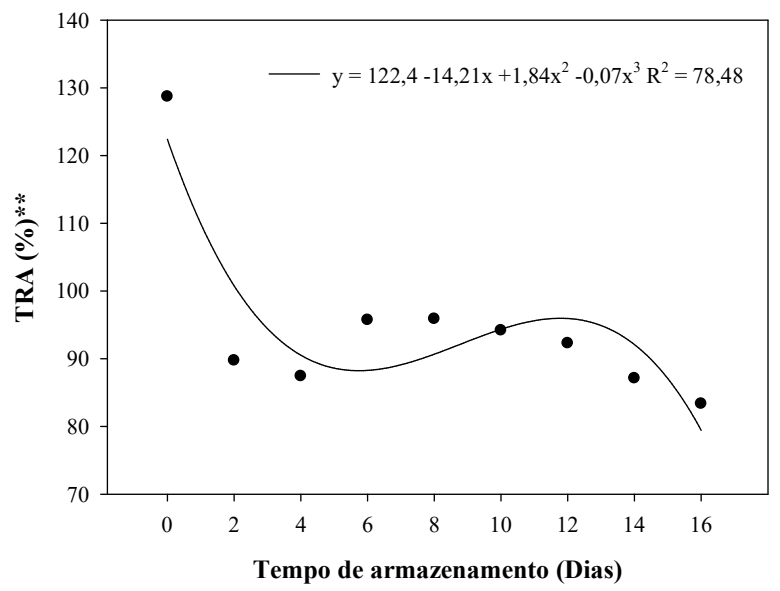

Figura 4. Efeito do tempo de armazenamento sobre o teor relativo de água (TRA - \%) de maços de folhas de cebolinha (Allium schoenoprasum). ${ }^{* *}$ : significativo ao nível de $1 \%$ de probabilidade pelo teste $F$.

O elevado teor relativo observado nas cebolinhas não hidroresfriadas e sem embalagem, se deve, possivelmente, à capacidade das folhas reabsorverem a água que foi perdida, por ainda estarem com seus tecidos jovens nos primeiros dias de armazenamento, visto que o equilíbrio entre ganho e perda de água nos tecidos das hortaliças é rompido após a colheita, o que ocasiona deficiência hídrica permanente, com perda gradual da turgidez dos tecidos (ÁLVARES, 2006). É importante lembrar que a manutenção do turgor celular é fundamental para a conservação da vida útil dos produtos hortícolas, uma vez que o balanço hídrico é o principal fator determinante da longevidade das folhosas (TAIZ \& ZEIGER, 2015), além disso, a falta de água no organismo acelera a senescência (ÁLVARES, 2006). 
Observou-se redução no teor de clorofila ao longo do período de armazenamento, evidenciando que, independentemente do tratamento pós-colheita, o teor de clorofila das folhas foi influenciado pelo tempo de armazenamento a $10^{\circ} \mathrm{C}$ (Figura 5).

Os valores do teor de clorofila total foram de $3,223 \mathrm{mg} / \mathrm{g}$ de massa fresca nas folhas hidroresfriadas e armazenadas sem embalagem, $2,641 \mathrm{mg} / \mathrm{g}$ de massa fresca nas folhas sem hidroresfriamento sem embalagem e $2,383 \mathrm{mg} / \mathrm{g}$ de massa fresca nas hidroresfriadas e embaladas com filme PVC (Tabela 2). Podendo-se afirmar que o hidroresfriamento associado à embalagem filme PVC, bem como o armazenamento refrigerado, contribuíram para menor degradação da clorofila das folhas destes tratamentos. Similarmente, Cerqueira (2012) observou que pimentas acondicionadas em potes e em sacos de polietileno apresentaram os maiores valores de clorofila $\mathrm{a}$, b e total à temperatura de $8^{\circ} \mathrm{C}$.

Resultados como estes evidenciam o efeito da baixa temperatura sobre a diminuição do metabolismo do produto, o que consequentemente, promove o controle de processos degradativos (HEATON \& MARANGONI, 1996; CERQUEIRA, 2012), bem como a composição da atmosfera de armazenamento podem influenciar na taxa de perda da clorofila e amarelecimento das folhas e, consequente, senescência do produto (IMAHORI et al., 2004; FRANÇA, 2011).

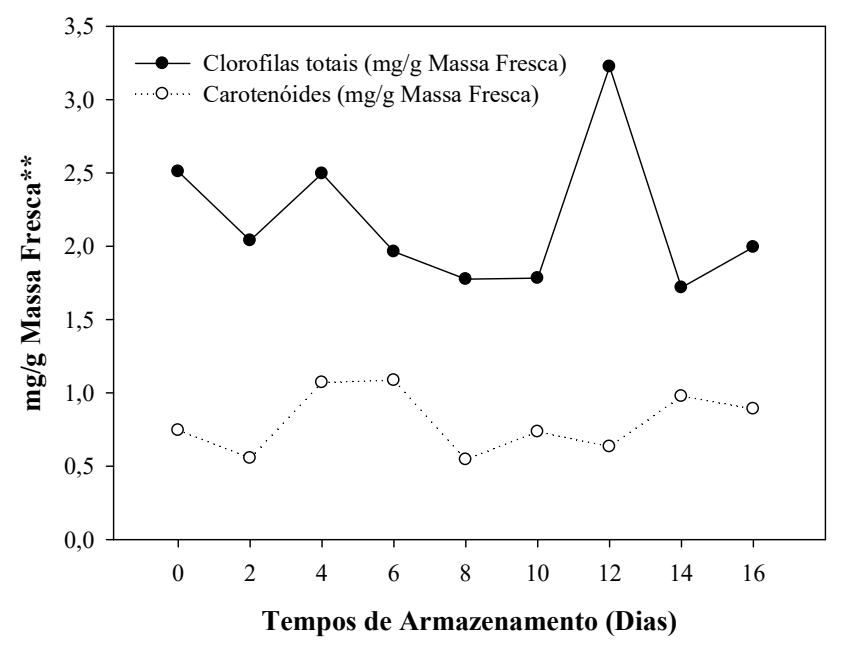

Figura 5. Efeito do tempo de armazenamento sobre o teor de clorofilas totais e carotenoides (mg/g de Massa Fresca) de maços de folhas de cebolinha (Allium schoenoprasum). ${ }^{* *}$ : significativo ao nível de $1 \%$ de probabilidade pelo teste $F$.

Nas folhas dos tratamentos sem hidroresfriamento foram observados os maiores valores de teor de carotenoides. O tratamento sem hidroresfriamento sem embalagem apresentou teor de carotenoides de 1,118 $\mathrm{mg} / \mathrm{g}$ de massa fresca das folhas, sendo este valor maior que os observados nos demais tratamentos (Tabela 2). Esse resultado mostra que o hidroresfriamento associado às embalagens foi efetivo em reduzir a degradação da clorofila, o que explica os menores teores de carotenoides observados nestes tratamentos.

\section{Conclusões}

As embalagens saco plástico e filme PVC, independente do pré-resfriamento, proporcionaram menor perda de massa e aumento de 16 dias na vida de prateleira das folhas de cebolinha. $O$ hidroresfriamento associado às embalagens e a temperatura de armazenamento foram eficientes em reduzir, temporariamente, a degradação da clorofila e o teor de carotenoides.

$\mathrm{O}$ teor relativo de água das folhas foi influenciado pelas condições e o tempo de armazenamento. $\mathrm{O}$ teor de clorofila das folhas reduziu ao longo dos dias de armazenamento à $10^{\circ} \mathrm{C}$, independentemente do tratamento aplicado. A adoção de embalagens saco plástico ou filme PVC associado ao hidroresfriamento por 30 minutos é uma alternativa viável para prolongar a vida pós-colheita das folhas de cebolinhas.

\section{Referências}


ÁLVARES, V.S. Pré-resfriamento, embalagem e hidratação pós-colheita de salsinha. 2006. $161 \mathrm{f}$. Dissertação (Doutorado em Fitotecnia) - Universidade Federal de Viçosa, Viçosa, MG, 2006.

ARRUDA, M.C.; BLAT, S.F.; OJEDA, R.M.; CALIXTO, M.C.; TESSARIOLI NETO, J. Conservação de raízes de beterraba cv. Early wonder sob atmosfera modificada. Revista brasileira Agrociência, v. 10, n. 2, p. 255257, 2004.

BECKER, B.R.; FRICKE, B.A. Hydrocooling time estimation methods. 2 ed. Amesterdã: Elsevier, 2002. 165-174 p.

CATSKY, J. Water content. In: SLAVIK, B. Methods of studying plants water relations. Berlin: Springer Verlag, 1974, p. 121-131.

CERQUEIRA T.S. Recobrimentos comestíveis em goiabas cv. "Kumagai”. 2007. 70f. Dissertação (Mestrado em Fisiologia e Bioquímica de plantas) - Escola Superior de Agricultura Luiz de Queiroz, Piracicaba, 2007.

CERQUEIRA, A.P. Conservação pós-colheita de pimentas-de-cheiro (capsicum chinense) armazenadas sob atmosfera modificada e refrigeração. 2012. 51f. Dissertação (Mestrado em Produção Vegetal) Universidade Federal do Tocantins, Gurupi, TO, 2012.

CHITARRA, M.I.F.; CHITARRA, A.B. Pós-colheita de frutas e hortaliças: fisiologia e manuseio. 2. ed. rev. e ampl. Lavras: UFLA, 2005. 785p.

CHRISTIE, G.B.Y.; MACDIARMID, J.I.; SCHLEIPHAKE, K.; TOMKINS, R.B. Determination of film requirements and respiratory behaviour of fresh produce in modifield atmosphere packaging. Postharvest Biology and Technology, Amsterdam, v. 6, p. 41-54, 1995.

FERREIRA, D.F. SISVAR: a computer analysis system to fixed effects split plot type designs. Revista Brasileira de Biometria, v. 37, n. 4, p. 529-535, 2019.

FERREIRA, M.D. Redução nas perdas pós-colheita em frutas e hortaliças: Um grande desafio. Embrapa Instrumentação - Capítulo em livro técnico (INFOTECA-E), 2017. Disponível em: < https://www.infoteca.cnptia.embrapa.br/infoteca/handle/doc/1084319> Acesso em 18/12/2018.

FILGUEIRA, F.A.R. Novo manual de olericultura: agrotecnologia moderna na produção e comercialização de hortaliças. 3. ed. Viçosa: UFV, 2008. 421p.

FINGER, F.L.; VIEIRA, G. Controle da perda pós-colheita de água em produtos hortícolas. Caderno didático 19. Viçosa: UFV, 29p, 1997.

FINGER, F.L.; ENDRES, L.; MOSQUIM, P.R.; PUIATTI, M. Physiological changes during postharvest senescence of broccoli. Pesquisa Agropecuária Brasileira. v. 32, n. 9, p. 1565-1569, 1999.

FRANÇA, C.F.M.; RIBEIRO, W.S.; SILVA, F.C.; COSTA, L.C.; RÊGO, E.R.; FINGER, F.L. Hydrocooling on postharvest conservation of butter lettuce. Horticultura Brasileira, v. 33, n. 3, p. 383-387, 2015.

GUSTAVSSON, J.; CEDERBERG, C.; SONESSON, U.; VAN OTTERDIJK, R.; MEYBECK, A. Global Food Losses and Food Waste Section. In: International Congress "Save Food!" at Interpack 2011, Düsseldorf, Germany. FAO, Rural Infrastructure and Agro-Industries Division, 2011. p. 29.

HEATON, J.W.; MARANGONI, A.G. Chlorophyll degradation in processed foods and senescent plant tissues. Trends Food Science Technology, v.7, p.8-15, 1996.

HEREDIA Z. N.A.; VIEIRA, M.C. Produção e renda bruta da cebolinha solteira e consorciada com espinafre. Horticultura Brasileira, Brasília, v. 22, n. 4, p. 811-814, 2004.

IMAHORI, Y.; SUZUKY, Y.; UEMURA, K.; KISHIOKA, I.; FUJIWARA, H.; UEDA, Y.; CHACHIN, K. Physiological and quality responses of Chinese chive leaves to low atmosphere. Postharvest Biology and Technology. v. 31, p. 295-303, 2004.

KADER, A.A.; ZAGORY, D.; KERBEL, E.L. Modified atmosphere packing of fruits and vegetables. Food Science and Nutrition, Hampshire, v. 28, p. 1-9, 1989. 
KALBASI-ASHTARI, A. Effects of postharvest pre-cooling processes and cyclical heat treatment on the physicochemical properties of "Red Haven Peaches" and "Shahmiveh Pears" during cold storage. Agricultural Engineering International: CIGR Journal, 2004.

KLUGE, R.A.; NATCHIGAL, J.C.; FACHINELLO, J.C.; BILHALVA, A.B. Fisiologia e manejo pós-colheita de frutas de clima temperado. Pelotas: UFPel, 2002. 214 p.

LAZAN, H.; MOHD ALI, Z.; Al'ANI MOHD; NAHAR, F. Water stress and quality decline during storage of tropical leafy vegetables. Journal of Food Science, v. 52, n. 5, p. 1286-1288, 1987.

LICHTENTHALER, H.K. Chlorophylls and carotenoids, the pigments of photosynthetic biomembranes. In: DOUCE, R.; PACKER, L. (Ed.). Methods in enzymology. New York: Academic, 1987. p. 350-382.

MACHADO, N.P.; COUTINHO, E.F.; CAETANO, E.R. Embalagens plásticas e refrigeração na conservação pós-colheita de jabuticabas. Revista Brasileira de Fruticultura, Jaboticabal - SP, v. 29, n. 1, p. 166-168, 2007.

MORETTI, C.L. Protocolos de avaliação de qualidade química e física de tomate. Embrapa Hortaliças, Brasília, DF. 2006. Comunicado técnico 32, 12p.

PARISI, M.C.M.; HENRIQUE, C.M.; PRATI, P. Perdas pós-colheita: um gargalo na produção de alimentos. Pesquisa \& Tecnologia, v. 9, n. 2, 2012.

SOUZA, M.T.A.; SANCHES, A.G.; MOREIRA, E.G.S.; CORDEIRO, C.A.M. Eficiência do hidroresfriamento na conservação e qualidade pós-colheita de coentro (Coriandrum sativum L.). Ciências Agrárias e Biológicas. Altamira - PA, v. 10, n. 01, p. 32 - 40, 2017.

SANTANA, K.F.A. Controle alternativo da antracnose em cebolinha (Allium fistulosum L.) utilizando produtos derivados de vegetais. 2015. 1-16 p. Dissertação (Mestrado em Agricultura no Trópico Úmido) Instituto Nacional de Pesquisas da Amazônia. Manaus - AM, 2015.

TRAVASSOS, A.P.; SILVA, E.N.; CRUZ, R.R.P.; SOARES, C.R.D.M.; MACÊDO, J.F.S.; RIBEIRO, W.S. Hidroresfriamento na conservação pós-colheita de cebolinha. Revista Brasileira de Agropecuária Sustentável, v. 7, n. 2, p. 46-51, 2017.

TAIZ, L.; ZEIGER, E. Fisiologia vegetal. 5 ed. Trad. Santarém, E. R. et. al. Porto Alegre: Artmed. 719p., 2015.

VILA, M.T.R. Qualidade pós-colheita de goiaba 'Pedro Sato' armazenados sob refrigeração e atmosfera modificada por biofilme de fécula de mandioca. 2004. 66f. Dissertação (Mestrado) - Universidade Federal de Lavras, Lavras, 2004.

WEATHERLEY, P.E. Studies in the water relation of cotton plant. In: The field measurement of water deficits in leaves. New Phytologist, v. 49, n. 1, p. 81-97, 1950.

WILLS, R.; MCGLASSOM, B.; GRAHAM, D.; JOYCE, D. Postharvest: and introduction to the physiology and handling of fruit, vegetables and ornamentals. 4 ed. New York: CAB International, 1998. 